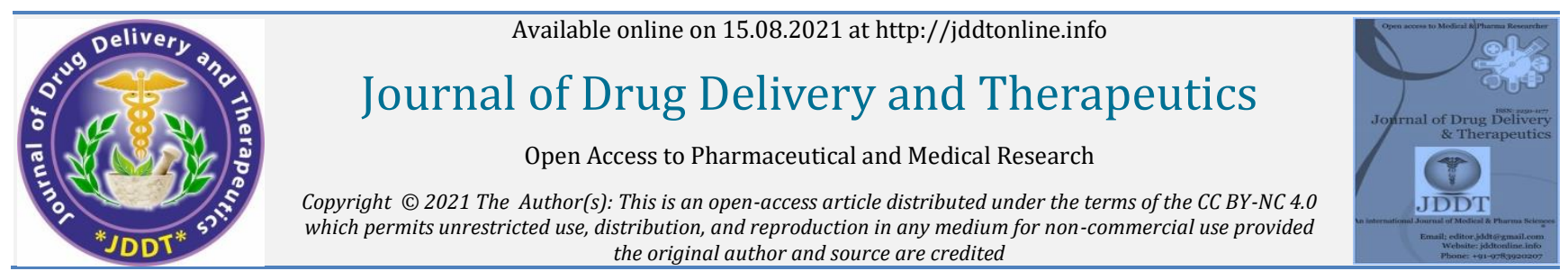

Open Access Full Text Article

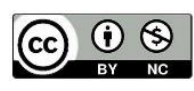

Review Article

\title{
Nanotechnology: A novel approach for treatment of skin disorder
}

Tamanna, Harmeet Singh* (D)

Faculty of Pharmaceutical Sciences, PCTE Group of Institutes, Ludhiana-142021, India

\begin{tabular}{|c|c|}
\hline \multicolumn{2}{|l|}{ Article Info: } \\
\hline 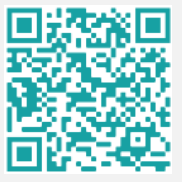 & $\begin{array}{l}\text { Received } 03 \text { May } 2021 \\
\text { Reviewed } 09 \text { June } 2021 \\
\text { Accepted } 19 \text { June } 2021 \\
\text { Published } 15 \text { August } 2021\end{array}$ \\
\hline \multicolumn{2}{|c|}{ Cite this article as: } \\
\hline \multicolumn{2}{|c|}{$\begin{array}{l}\text { Tamanna, Singh H, Nanotechnology: A novel } \\
\text { approach for treatment of skin disorder, Journal of } \\
\text { Drug Delivery and Therapeutics. 2021; 11(4- } \\
\text { S):271-277 }\end{array}$} \\
\hline \multicolumn{2}{|c|}{ DOI: http://dx.doi.org/10.22270/jddt.v11i4-S.4945 } \\
\hline \multicolumn{2}{|c|}{ *Address for Correspondence: } \\
\hline \multicolumn{2}{|c|}{$\begin{array}{l}\text { Harmeet Singh, Faculty of Pharmaceutical Sciences, } \\
\text { PCTE Group of Institutes, Ludhiana-142021, India }\end{array}$} \\
\hline ORCID ID: https: & 'orcid.org/0000-0003-0171-573X \\
\hline
\end{tabular}

\begin{abstract}
Skin, the integument system; pertaining to our body which consists of mainly three layers (i) Epidermis (ii) Dermis (iii) Subcutaneous Tissue. It acts as a protective barrier against many diseases and infections. Skin disorders vary greatly in symptoms and severity. Some may be attributed to situational causes while others may be genetic like atopic dermatitis, melanoma, acne vulgaris, wound healing and psoriasis. Conventional therapies are used to analyze various topical disorders suffers from many limitations i.e. less efficacy, poor patient compliance, and poor bioavailability. Therefore, novel approaches should be investigated for the development of better treatment of the disease. Novel carriers such as Liposome, Niosomes, Ethosomes, Silver nanoparticles, Solid lipid nanoparticles are utilized through almost all the routes of administration to treat dermatological disorders. These Nano systems are used to provide targeted drug delivery and a site-specific delivery of dosage form at a particular receptor site and thus enhance the uptake of poorly soluble drugs and overcome the issues related to poor bioavailability. The root cause for the development of such carriers lies on making the existing drugs more effective and safe for the patients.
\end{abstract}

Keywords: Skin, Skin disorders, NDDS, Novel Carriers, Nanotechnology

\section{Introduction}

Skin disorder was the fourth leading cause of disability worldwide in 2013. Skin disorders are one of the most common illness affect millions of people every day, occurs at all ages. It has been mainly caused due to many infectious pathogens or inflammatory conditions. Skin relating disorders enclose a vast variety of situations ranging in extremely from benign such as psoriasis to life threatening as in case of skin melanoma. Skin disorders vary considerably in symptoms and severity. Some may be attributed to situational causes while others may be genetic by dependent 1. These situations depend upon the types of pathogen involved, integrity of skin layers \& Structure. Recent variations have been made in the field of dermatology that suggests effective treatment of skin disorders i.e. requires timely identification, management and estimation of causative agent, efficient treatment and as well as route of administration $^{2}$. There are various infectious disease related to skin and hair follicles that is due to bacterial, fungal or viral infection and results in an eruption of skin surface. Chronic inflammatory diseases of skin such as psoriasis, atopic dermatitis and allergic contact dermatitis are the results of infiltration of inflammatory $\mathrm{T}$ cells with increased production of cytokines in the lesions ${ }^{3}$.These diseases are the significant cause of morbidity \& mortality. Skin ailments invent up to total of $1.79 \%$ to the global burden of disease measured in DALYs from 306 diseases \& injuries in 2013. Individual skin disorders extends in size from $0.38 \%$ of total burden for dermatitis (atopic, contact, and seborrhea ISSN: 2250-1177 dermatitis), $0.29 \%$ Vulgaris, $0.19 \%$ for psoriasis, $0.19 \%$ for urticaria, $0.16 \%$ for viral skin diseases where as for fungal skin infections i.e. $0.07 \%$ for scabies, $0.06 \%$ for malignant skin cancer, $0.05 \%$ \& $0.04 \%$ for Pyoderma \& cellulites, $0.03 \%$ for keratinocyte carcinoma, $0.03 \%$ for deceits ulcer, and $0.01 \%$ for Alopecia .All other skin \& subcutaneous diseases composed of total $0.012 \%$ DALYs.

\section{Skin}

Skin is the body's protective barrier against an entity of environmental invader against both of natural and anthropogenetic origins. Skin is also the primary surface for medical treatment and nursing care, ranging from transdermal drug delivery \& attachment of devices to keep an eye on various physiological functions, etc. Major role of the skin is to prevent invasion of microorganisms by creating a physical barrier from the external environment ${ }^{4}$. The defensive mechanism of skin not only presents physical protection but also extend immunological, metabolic and UV protection. 5

The skin consists of mainly three layers ${ }^{6}$

\section{Epidermis}

\section{Dermis}

\section{Subcutaneous Tissue}




\section{Epidermis-}

Epidermis is made up of Keratinocyte, but also accommodates the melanocyte \& dendrite cells such as Langerhans cells ${ }^{7}$. Nerve fibers have been demonstrated to stimulate all nucleated layers of epidermis. The nucleated cells of epidermis has three layers, the stratum basale (where stem cells as well as post mitotic, transiently amplifying cells are located) the stratum spinosum (or prickly layer), and the stratum granulosum. The keratinocyte develop structural proteins such as the epidermal keratin, the natural moisturizing factor (NMF), and the barrier lipid. It proliferate to heal the wounds or replace the corneocytes that are disoriented by exfoliation, transport water, glycerol and urea through the aquaporin, receive melanin from the melanocyte \& accommodate the antigen presenting Langerhans cells. The epidermis also secretes miscellaneous chemokine's, growth factors etc., for cellular transmission enclosed by the epidermis along with dermal cells (fibroblasts, mast cells) ${ }^{9}$.

\section{Dermis-}

Dermis consists of about $90 \%$ of the weight of skin. Dermis consists of connective tissue along with collagen fiber which provides support and flexibility. Below this, the layer is condensing10; having deeper reticulated layer which exhibits a dense connective tissue matrix with thick and regularly align bundles of fibrils. Hair follicles \& sweat glands enclosed in the dermis control the management of temperature ${ }^{9}$.The group of cells in the dermis are fibroblasts, which produce the extracellular structural proteins, collagen, elastin \& glycosaminoglycan the major water belonging components of the dermis ${ }^{19}$. Simultaneously, these components ${ }^{10}$ are known as the extracellular matrix.

\section{Subcutaneous Tissue -}

The subcutaneous tissue is also titled as hypodermis and is not considered as the part of the skin, and lies below the dermis ${ }^{12}$. Its purpose is to attach the skin to essential bone and muscle as well as supplying it with blood vessels and nerves ${ }^{13}$. It comprise of loose connective tissue \& elastin. The main cell types are composed of fibroblasts, macrophages and adipocytes. The subcutaneous tissue contains $50 \%$ of body fat. Fat serves as lining and insulation for the body.

\section{Disorders of the skin}

As skin sheath the external surface of the body. Skin contributes in thermoregulation; serve as water repellent and synthesis of many useful compounds like vitamin $\mathrm{D}^{25}$ and acts as a preventing barrier between external environment and internal tissue. There are different disorders of $\operatorname{skin}^{13}$ as mentioned in figure 1 .

1. Inflammatory skin diseases

2. Bacterial skin diseases

3. Viral skin diseases

4. Fungal skin disease

Epithelial layers and follicles consist of several important components as tight junction proteins whose localization and expression have been shown to be altered in the diseases characterized by a compromised skin barrier, such as psoriasis.

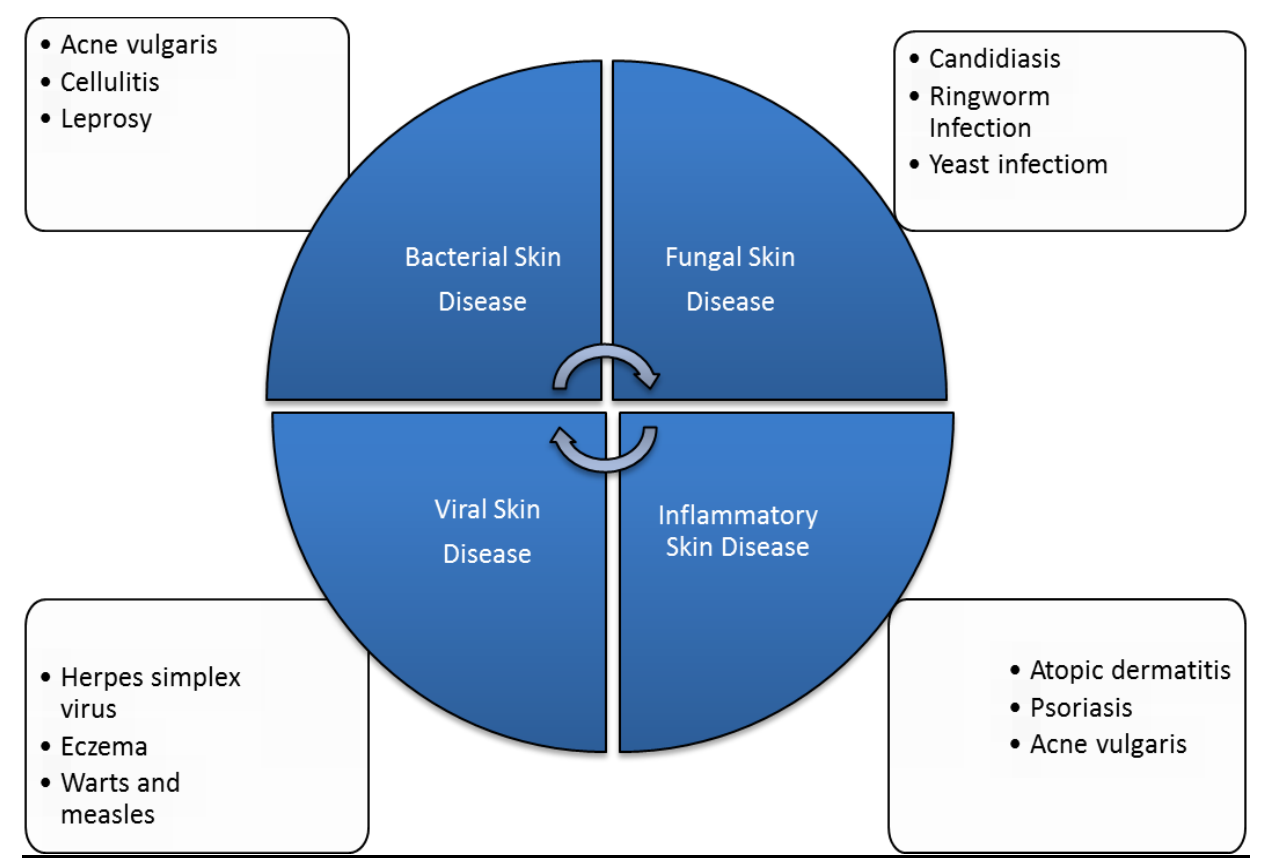

Figure1 Types of skin disorders

\section{Psoriasis}

Psoriasis is a T-cell mediated autoimmune inflammatory disorder i.e. acknowledged by skin surface inflammation, epidermal proliferation, which sometimes leads to hyperkeratosis, angiogenesis and anomalous keratinization also $^{14,23}$. It appears in a variety of manifestations such as plaque psoriasis, inverse psoriasis, pustular and erythrodermic psoriasis ${ }^{15}$.Relapsing \& spontaneous abeyance is a major problem associated with psoriasis.
Lymphocyte activation is the cause of psoriasis. Antigens attack the surface of antigen presenting cells in dermis and epidermis and forms MHC. Other cause is the risk factors in psoriasis which include abnormal alterations in eicosanoid metabolism, polyunsaturated fatty acids metabolic abnormalities and gene expression ${ }^{16}$.

\section{Atopic dermatitis}

Atopic dermatitis is also known as Atopic eczema .It is a type of inflammatory skin disorder characterized by severe 
itching and repetitive eczematous lesions ${ }^{7}$. Pathogenesis of this disorder is not completely known. It appears to result from the complex interaction between the defects in skin barrier functions, environmental factors, infectious agents and immune abnormalities ${ }^{18}$. Reactive oxygen species plays a major role in atopic dermatitis .Clear fluid come from the affected areas which often thicken over time. The condition may occur at any age, it normally starts in childhood with changing severity over the years 16,19 .

\section{Impaired Wound healing}

Non-healing wounds are the results in inhibition of the normal sequence of cellular and biochemical events towards the fixing of the skin's integrity. Factors delaying wound healing include diabetes, immunosuppression etc $^{20} . \mathrm{A}$ excessive and prolonged proteolytic activity results in the degradation of growth factors, considering wound in the inflammatory stage for too long ${ }^{21}$.Wounds that do not heal within 3 months are called or considered as chronic wound. In acute wounds, production \& degradation of molecule such as collagen is lost ${ }^{17} \&$ as in chronic wounds balance is lost and degradation plays a large role in healing.

\section{Acne Vulgaris}

Acne Vulgaris exist as a chronic disorder of the pilosebaceous follicles of the skin. The lesions of acne consist of comedones, erythematous papules and pustules, nodules \& cysts, and scarring ${ }^{23}$. The root cause of acne Vulgaris is the comedo and is initiate by hyperkeratosis of the lining of the pilosebaceous follicles with recognition of keratin and sebum. A closed comedo is known ${ }^{10}$ as a "whitehead" and an open comedo is called a "blackhead", the black color being due to melanin. The comedo is a non-inflamed lesion and it usually relapse automatically with little or faded scarring24. Certain diseases which block passage through the follicular pores for example hidadenitis, suppurativa \& necrotizing cellulites of the scalp, perhaps related with acne.

\section{Melanoma skin cancer}

Skin cancers are of different types based on cells that become malignant ${ }^{7}$. Melanocyte exists as a melanin-producing cell located inside basal layer of the epidermis. When it functions normally, the melanocyte comes up with basic skin pigmentation and defends against UVradiation ${ }^{25}$. Melanoma is more acceptable to occur and proliferate to other parts of the body. When skin cancer cells spread, they escape from the original growth and enter blood vessels or lymph vessels. Therefore the cancer cells may be found in nearby lymph nodes. These are primarily tumors that affect adult and elderly patients ${ }^{26}$.

\section{Stages of Melanoma}

These are the stages of melanoma:

- Stage 0: In this stage, melanoma involves only the top layer of skin. It is called melanoma in situ.

- Stage I: In this stage, the tumor is no more than 1 millimeter thick. The surface may acts broken down. The tumor is between 1 and 2 millimeters thick and the surface is not seemed broken.

- Stage II: In this stage, tumor is in between 1 and 2 millimeters thick \& the surface acts broken down. Or, the thickness of the tumor is more than 2 millimeters and the surface may seem broken.

- Stage III: In this stage, the melanoma cells run into at least one of the nearby lymph node or the melanoma cells that have spread from the original tumor to adjacent tissues.
- Stage IV: In this stage, Cancer cells have spread to the lung or other organs such as skin areas or lymph nodes that are far away from the original growth. It commonly spread to further parts of the skin, tissue under the skin, lymph nodes, and lungs. It can also broaden to the liver, brain, bones, and other organs.

\section{Conventional Therapies}

An ideal dosage regimen in the drug therapy of any disease is one which immediately measured the desired therapeutic concentration of drug in plasma ${ }^{15}$ by maintaining its concentration for the entire duration of treatment $\&$ is possible through the administration of conventional dosage forms in a particular dose \& at particular time 24 . But it has some limitations; Conventional topical therapies suffers from the limitations and are compromised (settled) with regard to patient compliance, safety and efficacy of the therapy. Traditional therapies are used to perform an action on the outer surface of the skin ${ }^{7}$. Conventional topical cures of the skin imply the use of ointments or creams. Drugs from preparations such as ointments, creams, lotions when applied on the skin produced a concentrated layer of active ingredient that is rapidly absorbed and results in poor patient compliance due to problems like stickiness and greasiness and may also sometimes cause irritation and allergic reactions. The delivery from these therapies is nonspecific and skin penetration is very low. Distinct drawbacks involve uncontrolled evaporation of active ingredient and unpleasant odor. Like in psoriasis normal moisturizing factors (NMFs) i.e. water is almost absent in the psoriatic skin ${ }^{27}$. As a result of various factors i.e. targeting the psoriatic tissues using topical route possesses a big challenge. Other topical therapeutic agents like liposomes are available for the treatment of psoriasis. In spite of these, none of them can be regarded as an ideal drug molecule ${ }^{28}$. This may either be due to their inherent side effects or their improper concentration in the conventional vehicles. In some skin disorders, use of penetration enhancers increase transport rate through the epidermal barrier but in addition, it also increases unwanted effects due to an enhanced drug level in the blood 31 . Unpleasant or even toxic side effects of penetration enhancers examine their use in topical drug administration 21, 29 .

\section{Novel Drug Delivery Systems for Skin Disorders [NDDS]}

The NDDS with their unique aspects provide suitable skin interactions as desired in the diseased conditions ${ }^{5}$. Scrutinize the benefits; there have been several recent attempts are used in NDDS approach to improve the existing topical drug formulations in Skin disorders ${ }^{74}$. Novel carriers such as Liposome, Niosomes, Ethosomes, Silver nanoparticles, Solid lipid nanoparticles have been utilize through almost all the routes of administration because of less painful effects as given by injections. However, the topical route has been used as one of the most appropriate substances to treat dermatological disorders more effectively ${ }^{27}$. In spite of the conventional formulations based on creams \& ointments, these novel dermatological systems are different in their composition \& concentration ${ }^{26}$. Several pharmaceutical and dermatological variables influence the choice of the system as per the need of the drug and disease. The applications of such novel Nano-vehicle systems are able to deliver potent drugs to the preferred site in a very accurate manner ${ }^{31}$. The composition of Nano medicines based on Nano systems; apparently control the release of a therapeutic moiety to the affected region at the skin site with localized effect by 
creating skin reservoirs. Such a fact that skin acts even as negatively charged membrane; the existence of charge on the surfaces of Nano carriers influences their drug diffusion through the skin. A positively charged delivery system would strongly interact with cells \& has shown better permeability and prolonged pharmacological activity 32,33 .

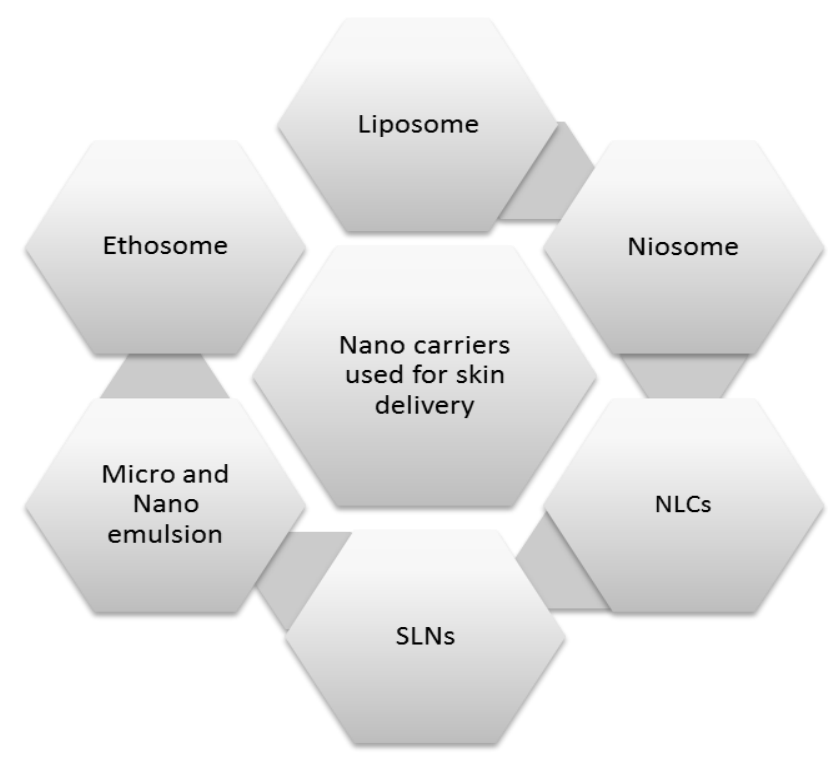

Figure 2 Novel approaches to treat various skin disorders

\section{Novel Formulations-}

Development of nanotechnology has been explored for treatment and diagnosis of various skin related diseases ${ }^{33}$ as given in table 1.1.

Table 1 Novel formulation for different skin disorders

\begin{tabular}{|c|c|c|c|c|}
\hline Types of dosage form & Drug & Disease & Study findings & Ref \\
\hline Liposome & Methotrexate & Psoriasis & Improved therapeutic index & 34 \\
\hline Ethosome & Methotrexate & Psoriasis & Favorable skin permeation characteristics 5 & 35 \\
\hline Niosome & Methotrexate & Psoriasis & Better efficacy and tolerance & 36 \\
\hline Liposomes & Dithranol & Psoriasis & Higher solubility & 37 \\
\hline Niosomes & Dithranol & Psoriasis & Better permeation & 38 \\
\hline $\begin{array}{l}\text { Liquid crystalline } \\
\text { nanoparticles }\end{array}$ & Tacrolimus & Psoriasis & Higher solubility, Better anti-inflammatory & 39 \\
\hline Microemulsion & Tacrolimus & Psoriasis & Higher drug skin penetration 4 & 40 \\
\hline Ethosomes & Resveratrol & Psoriasis & High permeation & 41 \\
\hline Liposomes & Resveratrol & Psoriasis & Higher stability and loading efficiency ${ }^{4}$ & 42 \\
\hline Transfersomes & Resveratrol & Psoriasis & High permeation & 43 \\
\hline Nano lipid carrier & Tacrolimus & Atopic dermatitis & Enhance drug solubility & 44 \\
\hline $\begin{array}{l}\text { Nanostructured lipid } \\
\text { carrier }\end{array}$ & $\begin{array}{l}\text { Betamethasone } \\
\text { dipropionate }\end{array}$ & Atopic dermatitis & Improved skin retention & 45 \\
\hline Polymer nanoparticles & Hydrocortisone acetate & Atopic dermatitis & Increase in therapeutic efficacy & 46 \\
\hline Nano emulsion & Clobetasol propionate & Atopic dermatitis & Increased anti-inflammatory activity & 47 \\
\hline Nano emulsion & Predincarbate & Atopic dermatitis & Increase retention time and bioavailability & 48 \\
\hline Nano emulsion & Nadifloxacin & Acne vulgaris & Improved zone inhabitation & 49 \\
\hline Nano emulsion & Dapsone & Acne vulgaris & Improved epidermal penetration & 50 \\
\hline Nano emulsion & Isotretinoin & Acne vulgaris & Controlled release & 51 \\
\hline Ethosomes & Econazole nitrate & $\begin{array}{l}\text { Skin fungal } \\
\text { infections }\end{array}$ & $\begin{array}{l}\text { Controlled drug release, better anti- } \\
\text { inflammatory activity }{ }^{1}\end{array}$ & 52 \\
\hline Solid lipid nanoparticles & Eugenol & Fungal infections & Increase in membrane permeability & 53 \\
\hline Microspheres & Insulin & Cutaneous wound & Promote tissue healing & 54 \\
\hline Polymeric micelles & Clotrimazole & $\begin{array}{l}\text { Superficial fungal } \\
\text { infections }\end{array}$ & Improved drug bioavailability $^{1}$ & 55 \\
\hline Microspheres & Benzoyl peroxide & Acne vulgaris & Favorable efficacy & 56 \\
\hline Solid lipid nanoparticles & Triclosan & Acne vulgaris & Increase stability & 57 \\
\hline
\end{tabular}




\section{Specific Nano formulations}

Nanotechnology is at the leading stage of rapidly developing diseases for their treatment. Like in case of skin disorders for example Psoriasis ,Atopic dermatitis , impaired Wound healing ,Acne Vulgaris and so on ${ }^{1}$.Nano carrier based drug delivery are efficiently used to develop the effectiveness of therapeutic agents \& various Nano systems are utilized to treat skin disorders they are liposomes, inorganic nanoparticles, Niosomes ,Ethosomes, solid lipid nanoparticles, Transferosomes. Nanoparticles are used to provide targeted drug delivery and a site specific delivery of dosage form at a particular receptor site and thus enhance uptake of poorly soluble drugs and bioavailability ${ }^{58}$.

\section{Liposomes -}

Liposomes are the sort of novel drug delivery system consists of concentered bilayer lipid 8particles used for treating many skin disorders such as acne, melanoma etc. It improves drug deposition at a specific site of skin, reduces systemic absorption, improve therapeutic effect of drug thereby providing localized effect ${ }^{2}$. Formulations of these liposomes lead to better results in the treatment of acne as compared to conventional drug therapies by releasing the drug at a specific site and are more preferable for lipophilic drug59.R.Kumar et al., Prepared the liposomal formulation of finasteride for topical treatment of Acne Vulgaris \& objective is to increase skin permeation, deposition and stability of the drug which results in higher deposition of drug in the skin with increased permeability and stability was observed during evaluation 60 .

\section{Niosomes -}

Niosomes are also being classified among novel drug delivery system which consists of unilamellar and multilamellar vesicles and are encapsulated by non-ionic surfactants that increase skin penetration. When applied topically, Niosomes increase the residence time of the drug in epidermis. They also increase the horny layer properties by reducing Tran's epidermal water loss \& increase the smoothness via replenishing lost skin lipids. Niosomes possess higher chemical stability of the surfactants as that of phospholipids and can further be used in the preparation of liposomes ${ }^{61}$. Gupta et al., Studies the in vitro permeation and retention studies of topical niosomal gel containing a mixture of benzoyl peroxide and tretinoin were performed \& compared to the permeation, retention of cream and alcoholic solution containing the same active substances as the niosomal gel ${ }^{3}$. Moreover anti-acne activity of the niosomal gel \& cream containing the same combination was evaluated. The results have shown that the drug retention was higher in case of niosomal gel than the cream and alcoholic solution. In vivo studies of the niosomal gel and anti-acne cream of tretinoin and benzoyl peroxide showed that the niosomal gel had greater efficacy than the anti-acne cream with niosomal gels ${ }^{3,62}$.

\section{Ethosomes--}

It is a type of novel drug delivery system which involves noninvasive delivery carriers that enables the drug to reach deep skin layers ${ }^{2}$. It mainly consists of phospholipids, water and high content of ethanol present in it. Due to the presence of ethanol in high concentration in Ethosomes it provides malleability to the vesicle membrane and enhances drug distribution in stratum corneum ${ }^{1}$. Ethosomes increase efficacy, therapeutic index, permeation to the skin, make drug more stable and soluble. Being noninvasive, ethosomal drugs have better patient compliance63.Verma $\mathrm{P}$ et al.,
Studies the preparation of nanosized ethanloic vesicles loaded with econazole nitrate for the treatment of fungal infections which results in controlled drug release ${ }^{1}$, better anti-fungal activity ${ }^{1}$ and good storage stability, ethosomal gel has tremendous potential to serve as topical drug delivery system 64 .

\section{Micro-emulsion and Nano-emulsion -}

These emulsions are Transparent and optically isotropic but micro emulsions are thermodynamically stable composed of oil, water, surfactants \& co surfactants whereas Nano emulsions are kinetically stable composed of oil, water, surfactants \& co surfactants 65 . Co-surfactants present in these emulsions act as penetration enhancer \& improve skin penetration 1 . Nano - emulsions are appropriate carrier for the transport of lipophilic compounds into the skin². They increase skin hydration and viscoelasticity ${ }^{66}$.R.P.Bagwe et al., Prepared lecithinised micro-emulsion as promising colloidal carriers allowing higher skin permeation ${ }^{3}$ and retention power of tretinoin compared to a solution, gel and marketed preparations containing this active substance ${ }^{67}$

\section{Solid lipid nanoparticles-}

Solid lipid nanoparticles are colloidal systems consists of triglycerides and waxes dissolved in surfactant solution to achieve physical stability ${ }^{1}$.These are also known as nanostructured lipid carriers ${ }^{68}$. Lipids present in these formulation increase bioavailability and reduce plasma profile variability. They have the ability to reflect and scatter UV radiation and acts as physical sunscreens on their own ${ }^{3}$. Lin et al., Prepared the lipid Nano carriers loaded with tretinoin and tetracycline into negatively charged lipid carrier resulted in a significant anti- bacterial activity 69

\section{Microspheres-}

Microspheres are spherical shaped particles made up of biodegradable polymer ${ }^{2}$.They are prepared by the Encapsulation technique which provide fine, inert, synthetic polymer materials deposited around solid and liquid micronized particles ${ }^{70}$. Microspheres absorb sebum from the skin surface, reduce oil from the skin and provide good efficacy and tolerability. They increase the therapeutic effect for the long term ${ }^{2}$. When microspheres are used as the drug carrier system they have numerous advantages in dermatology and cosmetology. D. Rasool et al. prepared the gelatin microsphere for the controlled release of all transretinoic acid for topical formulation of acne $\mathrm{e}^{71}$.

\section{Inorganic Nanoparticles-}

Inorganic nanoparticles such as gold, silver, metallic nanoparticles exhibit a wide range of applications in treatment of skin disorders. Silver nanoparticles have antimicrobial and anti-cancer activity as well as antiinflammatory activity ${ }^{34}$. AgNPs reduce the production of pro-inflammatory cytokines such as interlukin-6, tumor necrosis factor-alpha and inhibit the pathway of growth factor that increases the permeability of endothelial cells. They promote wound healing through reduction of the cytokine- modulated inflammation ${ }^{72}$. Garg.S et al. prepared the silver nanoparticles hydrogel using Arnebia nobilis root extract for wound healing activity. It shows good antibacterial property 73 .

\section{Conclusion}

In the present scenario the nanotechnology has been extensively investigated for developing the treatment strategies for the disease related to skin. It has already 
proven successful in disease other than skin related disorders and provides a very wide scope.

\section{REFERENCES}

1. Bissett DL. Anatomy and biochemistry of the skin. In: Kydonieus F, Berner B, editors. Transdermal Delivery of Drugs, 1987. p. 2942.

2. Gupta M, Agrawal U, Vyas SP. Nano carrier based topical drug delivery for the treatment of skin disorders,2012;9(7):783-804.

3. Dawson AL, Dellavalle RP, Elston DM. Infectious skin diseases: a review, 2012 Jan 1; 30(1):141-51.

4. Roberts MS, Walters KA. Human skin morphology and dermal absorption, 2008. p. 1-15.

5. Matsui T, Amagai M. The formation, structure and barrier function of the stratum corneum. International immunology. 2015; 27:269-280. https://doi.org/10.1093/intimm/dxv013

6. Wysocki AB. Skin anatomy, physiology, and pathophysiology. The Nursing clinics of North America. 1999; 34:777-797.

7. Eckhart L, Lippens S, Tschachler E, Cell death by cornification. Biochimica et Biophysica Acta (BBA)-Molecular Cell Research. 2013 Dec 1; 1833(12):3471-80.

8. Sahu SK, Raj R, Raj PM, Alpana R. Topical Lipid Based Drug Delivery Systems for Skin Diseases: A Review. Current Drug Therapy. 2020 Aug 1; 15(4):283-98.

9. Bouwstra JA, Honeywell-Nguyen PL,Skin structure \& mode of action of vesicles. Advanced drug delivery reviews. 2002 Nov 1; 54:S41-55.

10. Tansey EA, Johnson CD. Recent advances in thermoregulation,Advances in physiology edu Schaefer H, Redelmeier TE. Skin Barrier: Principles of Percutaneous Absorption. Karger, Basel; 1996.

11. Schaefer H, Redelmeier TE. Skin Barrier: Principles of Percutaneous Absorption. Karger, Basel; 1996

12. Lawlor KT, Kaur P. Dermal contributions to human inter follicular epidermal architecture and selfrenewal. International journal of molecular sciences. 2015; 16:28098-28107. https://doi.org/10.3390/ijms161226078

13. Saini S, Dhiman A, Nanda S. Traditional Indian medicinal plants with potential impaired wound healing activity: a review. International Journal of Pharmaceutical Sciences and Research 2016 May 1; 7(5):1809.

14. Goon AT, Yosipovitch G, Chan YH, Barrier repair in chronic plaque-type psoriasis. Skin research and technology ;journal of International Society for Bioengineering and the Skin, 2004; 10:10-13.

15. Rahman M, Akhter S, Ahmad J, Nanomedicine-based drug targeting for psoriasis: potentials and emerging trends. Expert opinion on drug delivery. 2015 Apr 3; 12(4):635-52.

16. Katare OP, Raza K, Singh B, Dogra S. Novel drug delivery systems in topical treatment of psoriasis, Indian Journal of Dermatology, 2010 Nov 1;76(6):612.

17. Thomsen SF. Atopic dermatitis: natural history, diagnosis, and treatment. ISRN allergy. 2014 Apr 2; 2014.

18. Thomsen SF. Atopic dermatitis: natural history, diagnosis, and treatment. ISRN allergy. 2014 Apr 2; 2014.

19. Hoare C, Po ALW, Williams H. Systematic review of treatments for atopic eczema. Health Technol. Assess. 2000; 4: 1-191.

20. Saini S, Dhiman A, Nanda S. Traditional Indian medicinal plants with potential wound healing activity: a review. International Journal of Pharmaceutical Sciences and Research. 2016 May 1; $7(5): 1809$.

21. Garg HG and Longaker MT: Scarless Wound Healing. Marcel Dekker, New York, 2000: 1-22. 4.
22. Reinke JM, Sorg H. Wound repair and regeneration. European Surgical Research. 2012; 49(1):35-43. https://doi.org/10.1159/000339613

23. Bowe WP, Glick JB, Shalita AR. Updates on topical and oral therapies for acne. Current Dermatology Reports. 2012 Sep 1 1(3):97-107.

24. Basic skin structure

25. Rigon RB, Oyafuso MH, Fujimura AT, Nanotechnology-based drug delivery systems for melanoma anti tumoral therapy: a review. BioMed research international. 2015; 2015.

26. Lloyd-Hughes $\mathrm{H}$, Shiatis AE, Current \& future nanotechnology applications in the management of melanoma: a review. Journa of Nanomedicine , 2015 Nov 1; 6(6):1.

27. Nacht S, Katz M. The microsponge: A novel delivery system.Drugs and the pharmaceutical sciences. 1990; 42:299325 .

28. Schmid MH, Korting HC. Therapeutic progress with topical liposome drugs for skin disease. Advanced drug delivery review, 1996 Feb 8;18(3):335-42.

29. Teichmann A, Heuschkel S, Jacobi U,Comparison of stratum corneum penetration and localization of a lipophilic model drug applied in an o/w microemulsion. Eur J Pharm Biopharm, 2007; 66:159-64.

30. Das R, Nath SS, Bhattacharjee R.,Optical properties of linoleic acid protected gold nanoparticles. Journal of Nanomaterials. 2011 Jan 1.

31. Nacht S, Katz M. The microsponge: a novel topical programmable delivery system. Drugs and the pharmaceutical sciences. 1990; 42:299-325.

32. Martin P, Youenang P, Daniel K, Positively and negatively charged submicron emulsions for enhanced topical delivery of antifungal drugs. 1999; 58:177-87.

33. Vyas A, Kumar Sonker A, Gidwani B. Carrier based drug delivery system for treatment of acne. The Scientific World Journal, 2014

34. Trotta M, Peira E, Carlotti ME, Deformable liposomes for derma administration of methotrexate. Int J Pharm 2004; 270:119-25. https://doi.org/10.1016/j.ijpharm.2003.10.006

35. Dubey V, Mishra D, Dutta T, Dermal and transdermal delivery of an anti-psoriatic agent via ethanolic liposomes. J Control Release 2007; 123:148-54. https://doi.org/10.1016/j.jconrel.2007.08.005

36. Lakshmi PK, Devi GS, Bhaskaran S, Sacchidanand S. Niosomal methotrexate gel for the treatment of localized psoriasis, 2007; 73:157-61.

37. Agarwal R, Saraswat A, Kaur I, A novel liposomal formulation of dithranol for psoriasis, 2002; 29:529-32.

38. Agarwal R, Katare OP, Vyas SP,Preparation \& in vitro evaluation of liposomal/niosomal delivery systems for antipsoriatic drug dithranol. Int J Pharm2001; 228:43-52.

39. Thapa RK, Baskaran R, Madheswaran T,Preparation, characterization and release study of tacrolimus-loaded liquid crystalline nanoparticles. J Disp Sci Technol 2013; 34:72-7. https://doi.org/10.1080/01932691.2011.648462

40. Wohlrab J, Goebel A, Scherer D, topical tacrolimus microemulsion for plaque-type psoriasis therapy, 2012.

41. Scognamiglio I, De Stefano D,Campani V, Nanocarriers for topical administration of resveratrol:a comparative study. Int J Pharm2013; 440:179-87.

42. Pando D, Caddeo C, Manconi M, Nanodesign of olein vesicles for the topical delivery of the antioxidant resveratrol. J Pharm Pharmacol 2013; 65:1158-67. https://doi.org/10.1111/jphp.12093 
43. Scognamiglio I, De Stefano D,Campani V, Nanocarriers for topical administration of resveratrol:a comparative study. Int J Pharm2013; 440:179-87.

44. Pople PV and Singh KK,Development and evaluation of colloidal modified lipid carrier: Application to topical delivery of tacrolimus. Eur J Pharm Biopharm. 2011; 79:82-94. https://doi.org/10.1016/j.ejpb.2011.02.016

45. Fang L, Kong X, Zhao Y, Quan P. Development of a topical ointment of betamethasone dipropionate loaded nanostructured lipid carrier. Asian J Pharm Sci. 2016; 11:248254. https://doi.org/10.1016/j.ajps.2015.07.005

46. Rosado C, Silva C, Reis CP, Hydrocortisone-loaded poly ( $\varepsilon$ caprolactone) nanoparticles for atopic dermatitis treatment. Pharm Dev Technol. 2012; 1-9.

47. Alam MS, Ali MS, Alam N, In vivo study of clobetasol propionate loaded Nanoemulsion for topical application in psoriasis and atopic dermatitis, 2013; 5: 8-12.

48. Keck CM, Baspinara Y, Borcherta HH. Development of a positively charged prednicarbate nanoemulsion. Int J Pharm. 2010; 383: 201-208. https://doi.org/10.1016/j.ijpharm.2009.09.002

49. Kumar A, Agarwal S, Ahuja A, Ali J, Preparation, characterization and in vitro antimicrobial activity of nanocarrier based formulation of nadifloxacin for the treatment of acne. Die Pharmazie-Int. J Pharm Sci. 2011.

50. De Almeida Borges VR, Simon A, Sena ARC, Nanoemulsion containing dapsone for topical administration: a study of in vitro release and epidermal permeation. Int J Nanomedicine. 2013; 8:535.

51. Miastkowska M, Sikora E, Ogonowski J, The kinetic study of isotretinoin release from nanoemulsion,Physicochemical and engineering Aspects. 2016 Dec 5; 510:63-8.

52. Verma P, Pathak K,Nanosized ethanolic vesicles loaded with econazole nitrate for the treatment of deep fungal infections through topical gel formulation, 2011.

53. Garg A, Singh S, Enhancement in antifungal activity of eugenol in immune suppressed rats through lipid nanocarriers.Biointerfaces. 2011 Oct 15; 87(2):280-8.

54. Michael H, Manuela M-G,Barron Annelise E, Sustained prolonged topical delivery of bioactive human insulin for treatment of cutaneous wounds. Int J Pharm 2010; 398:146-54. https://doi.org/10.1016/j.ijpharm.2010.07.052

55. Bachhav YG, Mondon K, Kalia YN, Novel micelle formulations to increase cutaneous bioavailability of azole antifungal drug. J Control Release 2011; 153:126-32. https://doi.org/10.1016/j.jconrel.2011.03.003

56. Bikowski and J. Q. Del Rosso, "Case reports: benzoyl peroxide microsphere cream as monotherapy and combination treatment for acne," Journal of Drugs in Dermatology, 2008; 590-595.

57. C. L. Dom'ınguez-Delgado, I. M. Rodr'iguez-Cruz, J. J. Escobar Chavez, "Preparation and characterization of triclosan nanoparticles used for the treatment of acne,"European Journal of Pharmaceutics and Biopharmaceutics, 102-107, 2.
58. Bawarski WE, Chidlowsky E, Bharali DJ, Mousa SA. Emerging nanopharmaceuticals. Nanomedicine: Nanotechnology, Biology and Medicine. 2008 Dec 1; 4(4):273-82.

59. Patel SS. Liposome: A versatile platform for targeted delivery of drugs.2006; 4(5):1-5.

60. Kumar R, Singh B, Bakshi G, Katare OP. Development of liposomal systems of finasteride for topical applications. Pharmaceutical development and technology. 2007 Jan 1; 12(6):591-601.

61. Yadav JD, Kulkarni PR, Vaidya KA, Niosomes: a review. Journal of Pharmacy Research. 2011 Mar; 4(3):632-6.

62. Gupta, A., Singh, S., Kotla, N.G., Webster, T.J., Formulation and evaluation of a topical niosomal gel containing a mixture of benzoyl peroxide and tretinoin for anti acne activity, 2014; 24(10), 171-182.

63. Razavi H, Janfaza $S$,Ethosome,A nanocarrier for transdermal drug delivery. Journal of Paramedical Sciences, 2015; 6(2):2008-4978.

64. Nastiti CM, Ponto T, Abd E, Grice JE, Topical nano and microemulsions for skin delivery. 2017 Sep 21; 9(4):37.

65. Verma P, Pathak K. Nanosized ethanolic vesicles loaded with econazole nitrate for the treatment of deep fungal infections in topical gel formation. Nanomedicine: Nanotechnology. 2012 May 1;8(4):489-96.

66. Grampurohit, N., Ravikumar, P., Mallya, R., Microemulsions for topical use-a review. Ind. J. Pharm. Edu. Res. 2001; 45(1):100107.

67. R. P. Bagwe, J. R. Kanicky, B. J. Palla, P. K. Patanjali, "Improved drug delivery using microemulsions: Critical Reviews in Therapeutic Drug Carrier System, 2001, pp. 77-140.

68. Müller, R.H., Mäder, K., Gohla, S., Solid lipid nanoparticles (SLN) for controlled drug delivery, Eur. J. Pharm. Biopharm.2000; 50(1):161-177. https://doi.org/10.1016/S09396411(00)00087-4

69. Lin, C.H., Fang, Y.P., Al-Suwayeh, S.A., Percutaneous absorption and antibacterial activities of lipid nanocarriers loaded with drug for acne treatment, 2003; 36(2):276-286.

70. Del Rosso JQ, Benzoyl Peroxide Microsphere Formulations, The Journal of clinical and aesthetic dermatology. 2009 Sep;2(9):4654.

71. Dinarvand R, Rahmani EL, Farbod E. Gelatin microspheres for the controlled release of all-trans-retinoic acid topical formulation, Iranian Journal of Pharmaceutical Research. 2010; 20(1):47-50.

72. Chowdhury A, Kunjiappan S, Panneerselvam T, Nanotechnology and nanocarrier-based approaches on treatment of degenerative disorders. International nano letters. 2017 Jun 1; $7(2): 91-122$.

73. Garg S, Chandra A, Mazumder A, Mazumder R. Green synthesis of silver nanoparticles using Arnebia nobilis root extract and wound healing potential of its hydrogel. Asian Journal of Pharmaceutics (AJP), 2014; 8(2).

74. Prabhu S, Poulose EK. Silver nanoparticles: mechanism of antimicrobial action, synthesis, medical applications, and toxicity effects. 2012 Dec; 2(1):1-0. 